\title{
PENSANDO ASPECTOS DA EDUCAÇÃO DESTINADA A JOVENS E ADULTOS A PARTIR DE NICOLAS CONDORCET, JACQUES RANCIÉRE, MARCO RAUL MEJÍA E PAULO FREIRE
}

\author{
PENSANDO EN ASPECTOS DE LA EDUCACIÓN DIRIGIDA A JÓVENES Y \\ ADULTOS DE NICOLAS CONDORCET, JACQUES RANCIÉRE, MARCO RAUL \\ MEJÍA Y PAULO FREIRE
}

\begin{abstract}
THINKING ABOUT ASPECTS OF EDUCATION AIMED AT YOUNG PEOPLE AND ADULTS FROM NICOLAS CONDORCET, JACQUES RANCIÉRE, MARCO RAUL MEJÍA AND PAULO FREIRE
\end{abstract}

\author{
Dinamara Garcia FELDENS ${ }^{1}$ \\ Fernanda Bispo CORREIA ${ }^{2}$ \\ Perolina Souza TELES ${ }^{3}$
}

RESUMO: O presente artigo, embasado em fontes de natureza bibliográfica, pretende fazer um levantamento de aspectos trazidos pelas obras de Condorcet, Jacques Ranciére, Marco Raul Mejía e Paulo Freire relativos à concepção de educação destinada a jovens e adultos. Isso porque, se está considerando que tais preocupações foram, em alguma medida, incorporadas ao que hoje se concebe como EJA no Brasil. A escolha desses autores se deveu ao fato de eles mencionarem, em suas obras, a necessidade de uma educação que atinja a todos e não somente classes privilegiadas. Considerando que, no primeiro momento da história da Pedagogia, a educação formal era destinada a um público bastante específico, ou seja, brancos e burgueses oriundos da nobreza. Este texto busca trazer, mesmo que brevemente, o pensamento desses quatro importantes teóricos, que até os dias de hoje influenciam a concepção de educação destinada a jovens e adultos.

PALAVRAS-CHAVE: Educação de jovens e adultos. Emancipação. Instrução.

RESUMEN: El presente artículo, a partir de fuentes bibliográficas, pretende sondear apspectos aportados por los trabajos de Condorcet, Jacques Ranciére, Marco Raul Mejía y Paulo Freire sobre el concepto de educación dirigida a jóvenes y adultos. Esto se debe a que se está considerando que tales preocupaciones fueron, hasta cierto punto, incorporadas a lo que ahora se concibe como EJA en Brasil. La elección de estos autores se debe a que mencionan, en sus obras, la necesidad de una educación que llegue a todos y no solo a las clases privilegiadas. Mientras que, en el primer momento de la historia de la Pedagogía, la educación formal estaba dirigida a un público muy específico, es decir, blancos y burgueses

\footnotetext{
${ }^{1}$ Universidade Federal de Sergipe (UFS), Aracaju - SE - Brasil. Professora Permanente do Programa de PósGraduação em Educação. Doutorado em Educação Básica (UNISINOS). ORCID: https://orcid.org/0000-00016471-3876. E-mail: dinag.feldens@gmail.com

${ }^{2}$ Universidade Federal de Sergipe (UFS), Aracaju - SE - Brasil. Doutoranda no Programa de Pós-Graduação em Educação. ORCID: https://orcid.org/0000-0003-4363-580X. E-mail: nandabispo@academico.ufs.br

3 Universidade Federal de Sergipe (UFS), Aracaju - SE - Brasil. Mestrado em Educação. ORCID: https://orcid.org/0000-0001-7334-6553. E-mail: perolinasouza@hotmail.com
} 
de la nobleza. Este texto busca traer, aunque sea brevemente, el pensamiento de estos cuatro importantes teóricos, que hasta hoy influyen en la concepción de la educación dirigida a jóvenes y adultos.

$\boldsymbol{P A L A B R A S ~ C L A V E : ~ E d u c a c i o ́ n ~ p a r a ~ j o ́ v e n e s ~ y ~ a d u l t o s . ~ E m a n c i p a c i o ́ n . ~ I n s t r u c c i o ́ n . ~}$

ABSTRACT: This paper, based on bibliographical sources, intends to survey aspects brought by the works of Condorcet, Jacques Ranciére, Marco Raul Mejía and Paulo Freire regarding the concept of Adult and Youth Education. This is because, it is being considered that such concerns were, to some extent, incorporated into what is now conceived as EJA in Brazil. The choice of these authors was due to the fact that they mention, in their works, the need for an education that reaches everyone and not just privileged classes. Whereas, in the first moment of the history of Pedagogy, formal education was aimed at a very specific audience, that is, whites and bourgeois from the nobility. This text seeks to bring, even if briefly, the thoughts of these four important theorists, who until today influence the conception of education aimed at young people and adults.

KEYWORDS: Adult and youth education. Emancipation. Instruction.

\section{Introdução}

Ao nos determos às leituras dos autores aos quais nos dedicamos para a consecução deste artigo, percebemos que havia, naquelas obras, ideias muito atuais, passíveis de serem encontradas na configuração em que se acha a educação de jovens e adultos (EJA) como modalidade de ensino no Brasil. Assim, o primeiro autor que nos chamou atenção, por trazer uma ideia de necessidade de política pública para a população não escolarizada desde a infância, foi Nicolas Condorcet ${ }^{4}$, e, por isso, o incluímos entre os autores arrolados para compor esta pesquisa bibliográfica. Mais adiante iremos detalhar como era essa educação vislumbrada por tal autor.

Outro nome que compõe este texto é o de Jacques Rancière, pelo fato de ele defender que é possível estimular no aprendiz a sua capacidade emancipadora e, além disso, estimular o aluno a aprender aquilo que o mestre ignora, o que nos leva ao que esse autor denomina de

${ }^{4}$ Segundo Santos (2007, p. 8) o Marquês de Condorcet, "[...] foi um dos mais jovens filósofos iluministas e um dos mais envolvidos nas transformações que começaram a ocorrer na sociedade francesa no séc. XVIII. Estas transformações foram mudanças sociais e políticas, mas também alterações na própria ciência e no modo de fazer essa ciência. Conviveu e participou da revivescência filosófica do Século das Luzes [...]. Condorcet foi um aluno [dos mais relevantes filósofos iluministas - Diderot, Voltaire, D’Alambert, Rousseau], um herdeiro que gozou ativamente das heranças dos seus pais filósofos, [...], de forma que depois que seus mestres morreram, ele pôde levar avante alguns dos projetos de civilização e organização política da sociedade que esses filósofos pensaram. No mesmo homem residia o matemático (da Matemática Social, inclusive), o economista (que foi ministro do Antigo Regime), o filósofo (o último iluminista) e o homem político (deputado da Assembleia Legislativa da República Francesa no período revolucionário)."

RPGE- Revista on line de Política e Gestão Educacional, Araraquara, v. 25, n. 3, p. 2933-2946, set./dez. 2021. e-ISSN: 1519-9029 DOI: https://doi.org/10.22633/rpge.v25i3.15678 
igualdade de inteligências. Incluímos também Marco Raúl Mejía, o qual vai, numa perspectiva de Pedagogia Crítica, debruçar-se sobre a educação de jovens e adultos na América Latina num contexto mais atual.

Por fim, chamamos ao diálogo o mestre Paulo Freire, considerando-o como um marco teórico para os fundamentos da Educação de Jovens e Adultos (EJA) no Brasil, tal qual a concebemos atualmente, e como pensador de uma metodologia de ensino brasileira, que tem como princípio a educação dialógica, como instrumento de emancipação dos educandos. Assim, a partir desses autores será intentado um levantamento das preocupações manifestadas em suas obras, considerando que as mesmas foram incorporadas ao que hoje concebemos como EJA. Na próxima seção, trazemos aspectos legais relativos à essa modalidade de educação.

\section{A educação de Jovens e Adultos: situando-a na contemporaneidade}

Contextualizando para a realidade específica do Brasil, Costa e Machado (2017) ${ }^{5}$, com base no parecer CEB elaborado por Carlos Roberto Jamil Cury, $n^{\circ} 11 / 2000$, fazem um apanhado da legislação relativa à Educação de Jovens e Adultos, que vai desde o Brasil Imperial à Constituição de 1988. Assim, inserimos um recorte desse apanhado, para que possamos associá-lo à discussão pretendida com os autores supracitados.

Destaque-se o fato de, desde a constituição de 1824, conforme o citado parecer, já existir a presunção de que competia a todo cidadão "a instrução primária gratuita" (Art. 179, 32) (BRASIL, 2000, p. 13). Outro ponto a mencionar é que em 1879, o decreto 7.427 estabelecia uma reforma no ensino que criasse cursos noturnos destinados a adultos analfabetos, livres ou libertos do sexo masculino - frise-se -, englobando as mesmas matérias ofertadas pelos cursos diurnos. No entanto, a constituição de 1891 vai retirar de seu texto a questão da gratuidade apresentada na constituição imperial, além de exigir que o direito de voto não possa ser exercido por aqueles não alfabetizados. O documento cita que em 1925, o Decreto $\mathrm{n}^{0}$ 16.782/A (Lei Rocha Vaz, como ficou conhecido) determinava que a União deveria difundir o ensino primário, podendo 'ser criadas escolas noturnas, do mesmo caráter, para adultos'.

Muitos detalhes desse parecer do Conselho Nacional de Educação - Câmara de Educação Básica (CNE/CEB) - poderiam ser elencados neste texto, mas o que queremos agregar à discussão aqui pretendida é que, historicamente, desde 1934, já havia previsão de

${ }^{5} \mathrm{Na}$ verdade, trata-se de sistematização feita por Cury, em parecer da CEB no 11/2000. 
como a educação geral poderia ser estendida aos adultos, pois “A Constituição de 1934 [...] põe o ensino primário extensivo aos adultos como componente da educação e como dever do Estado e direito do cidadão" (COSTA; MACHADO, 2017, p. 59)

Outros momentos e documentos poderiam ser mencionados para mostrarmos como ocorreu a trajetória que configurou a EJA e como ela é formatada hoje, no entanto, optou-se por elencar a legislação mais basilar e recente a esse respeito, por isso, destaca-se a seguir parte do conteúdo da Seção V - da Educação de Jovens e Adultos - constante da Lei de Diretrizes e Bases da Educação (Lei n ${ }^{\circ}$ 9394/96), para, mais adiante, empreendermos as discussões em torno dessa temática:

\begin{abstract}
Art. 37 - A educação de jovens e adultos será destinada àqueles que não tiveram acesso ou continuidade de estudos no Ensino Fundamental e Médio na idade própria.

$\S 1^{\circ}$ - os sistemas de ensino assegurarão gratuitamente aos jovens e adultos, que não puderem efetuar os estudos na idade regular, oportunidades educacionais apropriadas, consideradas as características do alunado, seus interesses, condições de vida e de trabalho, mediante cursos e exames.

$\S 2^{\circ}$ - O Poder Público viabilizará e estimulará o acesso e a permanência do trabalhador na escola, mediante ações integradas e complementares entre si.

$\S 3^{\circ}$ - A educação de jovens e adultos deverá articular-se, preferencialmente, com a educação profissional, na forma de regulamento (BRASIL, 1996).
\end{abstract}

Assim, a LDB é responsável por regulamentar o previsto na Constituição Federal de 1988 em seu artigo 208, inciso I e é o documento a partir do qual o entendimento dessa modalidade pode ser melhor resumido e captado. ${ }^{6}$ Costa e Machado (2017, p. 64) vão mostrar que a educação de jovens e adultos, enquanto modalidade legitimada pela LDB e com base no que asseverou o parecerista do CEB, Carlos Roberto Jamil Cury, passará a ter perfil e feição especiais:

Trata-se pois de um modo de existir com característica própria. Esta feição se liga ao princípio da proporcionalidade para que este modo seja respeitado. A proporcionalidade, como orientação de procedimentos, por sua vez, é uma dimensão da equidade que tem a ver com a aplicação circunstanciada da justiça, que impede $\mathrm{o}$ aprofundamento das diferenças quando estas inferiorizam as pessoas. Ela impede o crescimento das desigualdades por meio do tratamento desigual dos desiguais, consideradas as condições concretas, a fim de que essas eliminem uma barreira discriminatória [...] significa que os estudantes da EJA também devem se equiparar aos que

${ }^{6}$ Além da LDB, podemos mencionar vasta documentação que trata da questão da educação de Jovens e Adultos para entender a configuração da educação de Jovens e Adultos, entre eles: a Declaração Mundial sobre Educação para Todos; Declaração e Plano de Ação de Viena; Agenda 21 (capítulo 36); Declaração de Copenhague (compromisso n ${ }^{\circ}$ 6); Plataforma de Ação de Beijing; Afirmação de Aman e Plano de Ação para o Decênio das Nações Unidas para a Educação na Esfera dos Direitos Humanos, entre outros.

RPGE- Revista on line de Política e Gestão Educacional, Araraquara, v. 25, n. 3, p. 2933-2946, set./dez. 2021. e-ISSN: 1519-9029 DOI: https://doi.org/10.22633/rpge.v25i3.15678 
sempre tiveram acesso à escolaridade e nela puderam permanecer (COSTA; MACHADO, 2017, p. 64).

Esse excerto mostra quais resultados a LDB vislumbra que a EJA venha a alcançar, na prática, demonstrando sua função essencialmente reparadora e equalizadora, e corroborando com o princípio encontrado na CF de 1988, "Educação como direito de todos e dever do Estado". Nesse mesmo sentido, encontramos nas Diretrizes Curriculares Nacionais para a Educação de Jovens e Adultos, aspectos que ressaltam a garantia de direitos sociais através do acesso a essa modalidade de ensino.

[...] a Educação de Jovens e Adultos (EJA) representa uma dívida social não reparada para com os que não tiveram acesso a e nem domínio da escrita e leitura como bens sociais, na escola ou fora dela, e tenham sido a força de trabalho empregada na constituição de riquezas e na elevação de obras públicas. Ser privado deste acesso é, de fato, a perda de um instrumento imprescindível para uma presença significativa na convivência social contemporânea (BRASIL, 2021, p. 05).

No tópico a seguir, verificaremos as convergências dos autores escolhidos frente às características do que apresentamos anteriormente, em termos legais, e do que hoje se entende por Educação de Jovens e Adultos no Brasil.

\section{Detectando pontos de convergência entre a Educação de Jovens e Adultos no Brasil e pressupostos observados na obra de Condorcet, Rancière, Mejía e Freire}

De certo modo, os quatro autores que compõem este artigo acreditam que a educação é um caminho possível de ser trilhado por todos e isso inclui o adulto que não recebeu a escolarização prevista durante a infância e que pode fazê-lo em outro momento. Três deles Rancière, Mejía e Freire - vão defender mais fervorosamente a emancipação, como fim do processo educacional.

Mejía, estudioso ao qual se deve o surgimento das primeiras iniciativas de educação popular na América Latina, faz um apanhado de acordo com o qual assevera que, no entremeio das duas guerras mundiais, houve uma acentuada preocupação com a educação de jovens e adultos, ressaltando que isso se deveu ao problema com os desempregados e camponeses que passaram a viver em regiões urbanas. Dessa forma, o operário, naquele momento, precisaria estar adaptado à tecnologia. Segundo Mejía (2018, p. 40), “[...] estas situações levaram a que uma infinidade de pessoas fosse reeducada, no sentido de adaptação às novas circunstâncias". 
Esse autor mostra que na América Latina foi a Agência Interamericana para o Desenvolvimento que trouxe para o continente americano (latino) “[...] a concepção de educação de adultos como aquela definida pela idade do destinatário e por desenvolver-se em processos não formais, diferenciando-se dos processos escolarizados, e estabelecendo-se uma distinção entre educação formal e educação não formal” (MEJÍA, 2018, p. 41). Mesmo com as legislações e toda a evolução por que passou a educação de adultos, ainda há, segundo o próprio Mejía, quem considere a educação de adultos como não formal.

Vemos aí que o que aponta Mejía está claramente posto no parágrafo $3^{\circ}$, do artigo 37 da LDB, o qual prevê a articulação da educação de jovens e adultos com a profissionalização. Além, disso, é importante destacar que Mejía (2018, p. 18), justamente por ser um autor da Pedagogia Crítica, manifesta em seu texto preocupações com as características do alunado, ainda mais porque esse autor acredita que o educando é um ator ativo, por isso argumenta:

[...] uma concepção de educação [...] tem práticas, metodologias, teorias, enfoques, pedagogias, e uma opção ética de transformação. [...] é parte de um projeto que busca dignificar o humano excluido e segregado por meios educativos e políticos pedagógicos como parte de construção de novos mundos (MEJÍA, 2018, p. 18. grifo nosso).

Essa perspectiva da Pedagogia Crítica vai perpassar toda a obra desse autor e é o ponto que queremos destacar em relação à nossa legislação de educação destinada a adultos, ou seja, uma visão dignificadora do homem excluído e segregado. Um importante destaque cabe ao fato de esse estudioso ressaltar que a educação popular não se restringe à educação de adultos, ainda que essa seja uma perspectiva bastante relevante em sua obra.

Além disso, um elemento importante apresentado pela obra de Mejía é a interculturalidade, isto é, o fato de a escuta do outro não poder ser desinteressada para que depois se diga o que é o certo. Assim, a educação popular não visa à superação de saberes, mas sim partir de diferentes culturas, respeitando-as. Compete aqui, mais uma vez, associar essa ideia ao que está previsto no artigo 37 da LDB: a promoção de “[...] oportunidades educacionais apropriadas, consideradas as características do alunado, seus interesses, condições de vida e de trabalho [...]."

Assim, a educação popular, como nos mostra Mejía, leva em consideração o nível de desenvolvimento subjetivo em que se encontra o grupo com o qual se vai trabalhar, visando, assim, fugir de metodologias únicas. Outro destaque que cabe fazer é o fato de o paradigma latinoamericano centrar sua proposta numa crítica à modernidade, visando a visibilizar as pedagogias do sul, as quais podem ser caracterizadas como "[...] formas de conhecer 
fundamentadas na cultura e no contexto, como terreno de diferenças e necessidade de que a educação construa atores críticos, promotores de transformação de suas realidades." (MEJÍA, 2018, p. 61). Mais uma vez, reforça-se a proposta contextualizada e transformadora, caráter do qual toda educação deveria ser revestida.

Em Condorcet, veremos que se acredita que o ensino dos diversos assuntos por ele defendidos como fundamentais (arte, economia rural, educação física e moral) devem ser ensinados após o ensino fundamental. Assim, ele defende que os adultos restritos à primeira instrução não conseguiriam buscar sua instrução nos livros. Assim, Condorcet (2008), argumenta que, para esses adultos,

O ensino ainda lhes é necessário. Poder-se-ia, pois, estabelecer que o professor encarregado dessa primeira instrução seria o mesmo encarregado de dar, a cada domingo, uma aula para a qual seriam admitidas as crianças, os jovens dos dois sexos, os pais e as mães de família. Porque é preciso ainda aqui evitar separar os homens das mulheres (CONDORCET, 2008, p. 172).

Para esse pensador, o dia de descanso desses homens ocupados, principalmente com trabalhos físicos, deveria ser um dia de estudo, que fosse dedicado a ocupações instrutivas, e assim, estar-se-ia utilizando de modo útil o dia que não fosse o de trabalho ordinário. Isso resultaria em uma forma de prestação de serviço à sociedade, segundo o próprio Condorcet. Vê-se, nesse excerto, a ideia embrionária de um forma alternativa para que o estudante trabalhador pudesse ter acesso à instrução, isso nos faz associar aos cursos noturnos da legislação atual que visam, justamente, a oportunizar o acesso desses alunos à escola. Dessa leitura de Condorcet, depreende-se que ele propõe não uma educação propriamente emancipatória, como veremos em Rancière, em Mejía e em Freire, mas um meio de os adultos serem melhor instruídos, ainda que a formalização dessa educação não esteja muito bem delineada em sua proposta.

Segundo Boto (1996, p. 127), "Em Condorcet, a perfectibilidade [...] estaria ameaçada, se não fossem empregados vigorosos esforços no sentido de erradicar a ignorância." É por isso que Boto (1996) argumenta que:

Condorcet manifesta para a instrução uma amplitude que pretende abranger todas as idades da vida, de maneira que os conhecimentos adquiridos na escola pudessem ser reavivados e mesmo atualizados por um projeto de formação continuada e permanente. Todos os cruzamentos discursivos confluem, nesse sentido, para a crença, sempre retomada, de uma desenvolução do tecido social pela erradicação do obscurantismo popular (BOTO, 1996, p. 121, grifo nosso). 
Por essa razão, segundo Boto (1996), constam do preâmbulo do relatório da proposta condorcetiana, apresentado à Assembleia Legislativa pela Comissão de Instrução Pública da França (séc. XVIII), os objetivos de levar os indivíduos a alcançarem o bem-estar, a se tornarem conscientes defensores dos seus direitos e capazes de cumprir seus deveres, capazes inclusive de desempenharem as funções sociais a que estariam naturalmente designados a serem chamados.

Em relação a este último aspecto, observa-se uma crença numa espécie de separação social por habilidades naturais. Desse modo, nem todos estariam destinados a ocupar todas as funções que desejassem, já que o indivíduo só seria capaz de desenvolver “[...] completamente os talentos que recebeu da Natureza." Santos (2007) mostra que, concernente ao debate sobre a instrução pública na época em que Condorcet elabora o relatório, como já mencionado, pós Revolução Francesa, era possível fazer diversas considerações

[...] tais como o grau de prioridade da instrução, quem deveria tomá-la a seu cargo é uma questão muito importante que diz respeito ao próprio modelo de instrução: de um lado alguns diziam que seria necessário formar homens fortes, esclarecidos e virtuosos e do outro lado afirmavam que se deveria instruir os homens até que eles pudessem se esclarecer por si mesmos. A diversidade do debate filosófico sobre a instrução pública se dá em torno da questão do modelo antropológico que deve representar o homem novo, este que surgiu na Revolução; é um debate em torno da ideia tanto de cidadania, quanto da ideia de direitos do homem. Este homem novo, como cidadão livre, não é mais súdito, agora é um cidadão que compartilha da igualdade com todos os outros cidadãos. O problema ao modelo educativo aparece, pois, em torno da ideia de cidadania, sobre sua extensão. No debate sobre a definição de cidadania ocorrem duas concepções: a primeira diz respeito à dependência do cidadão em relação ao Estado e a segunda diz respeito à liberdade do cidadão de constituir o Estado, porque esse Estado é o resultado de uma vontade fundadora (SANTOS, 2007, p. 92-93).

Ora, em que pese o debate sobre as duas propostas acima mencionadas, era nítida a ideia de Condorcet de favorecer que o homem, por meio de uma instrução que lhe coubesse (para os adultos trabalhadores, como é o foco deste artigo), conseguisse atingir sua liberdade e autonomia. Assim, esse autor defendia que, conforme aponta Boto (1996), “[...] virtudes e talentos seriam as únicas fontes legítimas de distinção social”. Outro destaque que a proposta condorcetiana merece é que se fazia primordial que o povo, por meio da instrução, pudesse conhecer os seus direitos, de forma que se sentisse consultado quando da elaboração das leis. Por isso, tirá-los da ignorância e fazê-los conhecedores de seus direitos seria o caminho para que fosse atingido tal objetivo. 
Incluímos Jacques Rancière (e seu Jacotot ${ }^{7}$ ) nesta breve discussão pelo fato de sua obra "O mestre ignorante: cinco lições sobre a emancipação intelectual" apresentar uma proposta de professor e de educação, capazes de emancipar as inteligências, considerando que que não há um "ignorante” que não saiba uma infinidade de coisas. Desse modo, ele acredita que e é sobre este saber, sobre esta capacidade em ato que todo ensino deveria se fundar. Em decorrência disso, selecionamos tal autor para pensarmos o que dessa perspectiva pode ser captado na educação de jovens e adultos atual.

Para Ranciére e sua perspectiva de igualdade de inteligências, "[...] se a igualdade não for estabelecida como ponto de partida, ou seja, colocada no início do processo, nada poderá ser feito para alcançá-la.” Assim, o embrutecimento, que ele contrapõe à emancipação, não atinge o povo por conta meramente da falta de instrução, mas o fato de se crer na inferioridade da própria inteligência. A emancipação do aluno, por sua vez, é entendida dentro daquilo que denomina o 'círculo da potência', no qual "[...] o ignorante aprenderá sozinho o que o mestre ignora, se o mestre acredita que ele o pode, e o obriga a atualizar sua capacidade". Além disso, ele acredita que quem reconhece que todo homem nasceu para compreender o que qualquer homem tem a dizer compreendeu o que é emancipação intelectual.

Refletindo sobre a perspectiva de Rancière, - quando o mesmo afirma que emancipar pelo menos um homem já é uma vitória e fio condutor para a mudança de estruturas - cabe mencionar também, a partir de Paulo Freire, que os professores não devem ensinar transferindo conhecimentos, mas criando condições e possibilidades para a construção que esse emerja, isso porque o ensinar não se desvincula do aprender. É por isso que esse pressuposto pode ser observado na LDB, considerando que essa lei determina que devem ser observadas "[...] oportunidades educacionais apropriadas, consideradas as características do alunado, seus interesses, condições de vida".

Paulo Freire sempre expressou a sua preocupação em formar cidadãos críticos, capazes de refletir sobre a realidade, de descobrir-se como "pessoa" e reconhecer-se como agente transformador da sociedade. Devemos buscar a construção de educadores subversivos, questionar/criar e não reproduzir conhecimento. Para Freire utopia é um sonho possível, sua pedagogia é pautada na autonomia.

Entretanto, Freire entendia o seu pensamento, mais como uma Teoria do Conhecimento do que, como uma metodologia de ensino, para ele sua obra significava muito

${ }^{7}$ Jacotot, representante de uma espécie de vanguarda utópica da pedagogia de sua época. 
mais um método de aprender, que um método de ensinar. O método Paulo Freire consiste numa proposta para a alfabetização de adultos que efetivou uma crítica ao sistema tradicional, o qual utilizava a "Cartilha" como ferramenta central da didática para o ensino da leitura e da escrita, pois essa ferramenta ensinava pela repetição de palavras soltas ou de frases criadas de forma forçosa.

O Método Freireano preocupa-se com a alfabetização dos educandos, possibilitando a sua inserção na história da humanidade, ajudando-os por meio da educação, na análise dos problemas da comunidade local e nacional. Os educandos "abrem os olhos" pois passam a compreender a vida de outro jeito. A utilização do diálogo, da partilha de conhecimentos e saberes tornam significantes a aprendizagem e configuram-se em estratégias básicas para o desenvolvimento do processo ensino-aprendizagem. Este, mesmo sem construir sentidos e significados para suas ações, emoções e pensamentos, perde o sentido de ser, pois o ser humano morre, inclusive fisicamente.

Segundo Carlos Rodrigues Brandão (1991), as etapas do Método Freireano estruturam-se em momentos que, pela sua natureza dialética, não são estanques, mas estão interdisciplinarmente ligadas entre si.

Na primeira etapa - denominada "As palavras geradoras" - Brandão afirma que o Método de Freire corresponde a um processo que se inicia pela investigação constante do universo vocabular dos educandos e pelo estudo dos modos de vida da população e de sua localidade. Através de conversas informais, o educador observa os vocábulos mais utilizados pelos alunos com o intuito de escolher criteriosamente àqueles que servirão de base para as lições. A quantidade de vocábulos ou palavras geradoras pode variar entre 18 e 23, aproximadamente. Esse mergulho na vida do educando possibilitará ao educador a condição de emergir da realidade do grupo-classe que está sendo investigado, dando-lhe condições de se entregar ao processo, ajudando-o a definir seu ponto de partida. Depois de composto o universo das palavras geradoras, passa-se a exercitá-las através da discussão sobre o tema gerado por elas. "As palavras são a menor unidade da pesquisa, assim como os fonemas das palavras serão a menor unidade do método. Mas aqui, as palavras não são só um instrumento de leitura da língua; são também instrumentos de releitura coletiva da realidade social onde a língua existe" (BRANDÃO, 1991, p. 30).

O método proposto por Paulo Freire utiliza-se também dos "círculos de cultura", termo que vem a substituir a sala de aula convencional, ou seja, como o próprio nome já indica, todos formam um círculo para que o alfabetizador (animador de debates) possa coordenar um trabalho voltado para o diálogo. Quanto a ser de "cultura", é por se tratar de 
produção coletiva onde todos aprendem palavra por palavra que fazem parte da vivência dos alfabetizandos, já que o conteúdo do diálogo refere-se ao conteúdo programático da educação.

Para Freire, o educador libertador deve buscar o conteúdo na cultura do educando e na consciência que este tem da mesma, depois disso, devolver esse conteúdo de forma organizada e estruturada. Esse método por ser dialógico, permite que o indivíduo tenha consciência sobre os temas, participe e investigue o seu próprio universo, admirando-o, podendo criticá-lo e transforma-lo. Contrariando o educador "bancário", que define o conteúdo antes mesmo do primeiro contato com o educando e apenas o deposita no educando.

Segundo Paulo Freire, a base da Pedagogia é o diálogo. Essa premissa está presente em diferentes situações entre o educador-educando e o objeto do conhecimento entre a natureza e cultura. Freire acreditava que a educação deveria ter como objeto a promoção da ampliação da visão de mundo do aluno e isso só seria possível através da ação mediatizadora do diálogo que deveria começar antes da situação pedagógica propriamente dita.

A segunda etapa seria a "Silabação" - após a identificação e seleção das palavras geradoras iniciava-se o seu estudo através da divisão silábica, nesse sentido, semelhante ao método tradicional: cada sílaba se desdobra em sua respectiva família silábica, pela mudança da vogal (parte que muda em cada família), as sílabas são lidas e repetidas por todos, que podem até escrever. Após essa fase, o educador faz uso da ficha de descoberta que contém as famílias e que lhe serve em vários momentos do processo: repetição, separação de famílias e cópia. Aqui será importante mostrar ao educando a articulação entre os valores sonoros das vogais para facilitar o reconhecimento das sílabas.

A terceira etapa é denominada por Brandão (1991) como “As novas palavras". Usando as famílias silábicas, agora conhecidas, o "grupo" forma novas palavras. Aqui o educador não insiste para que o educando escreva ou recrie palavras, ele apenas o incentiva, podendo ele próprio fazê-lo. Esse trabalho somente será interrompido quando o educador achar conveniente. É importante frisar que as palavras construídas pelo grupo também serão lidas por ele. As dificuldades serão apresentadas e discutidas. Mais a frente, por meio de incentivos, os alunos começam a formar frases curtas e/ ou períodos.

Por fim a quarta etapa, seria a "Conscientização". Para Freire, alfabetizar não pode se restringir aos processos de codificação e decodificação. Dessa forma, o objetivo da alfabetização de adultos é promover a conscientização acerca dos problemas cotidianos, a compreensão do mundo e o conhecimento da realidade social. Assim, os conteúdos (criados a partir de palavras geradoras) são resultado de uma metodologia dialógica. Nesse sentido, é preciso conhecer o educando enquanto indivíduo inserido num contexto social. A reflexão 
política, um dos aspectos desse método, proporciona a conscientização e culmina com a transformação cultural, ocorrendo a politização através de ações organizadas.

\section{Considerações finais}

Iniciamos estas palavras finais pela obra condorcetiana, muito marcante por se tratar de uma política pública de educação bastante revolucionária, pois que surge num contexto pós Revolução Francesa, e sistematizada, manifesta um caráter dual, pois o seu universalismo compreendia uma igualdade que possibilitasse a profissionalização dos pobres e a mantivesse a elitização educacional dos ricos. Isso nos leva a pensar que a atual configuração do que está estabelecido como EJA ainda manifesta esse viés de acomodação ao "lugar natural" e de talento que aquele cidadão estaria designado a ocupar.

É importante destacar também a importância da América Latina para a obra de Freire, assim como em Mejía, com ênfase no Sul como símbolo de resistência. Através da educação dialógica e da impressão do pensamento decolonial existente em sua obra, Paulo Freire vai de encontro às diversas formas de opressão em relação ao conhecimento - simbolizando luta e resistência - rumo à emancipação nos diversos níveis da sociedade. Com isso, esse emblemático pensador rompe com a coloneidade do ser e prega a descolonização das mentes.

Se por um lado Rancière traz o Ensino Universal, como método de ensino capaz de acelerar o processo de instrução popular, Freire propõe um método de ensino dialógico, que busca emancipar os homens através da educação. O Método Freireano tem como fio condutor a alfabetização visando a libertação que não se dá apenas no campo cognitivo, mas, principalmente, nos campos social e político.

Vislumbrando a perspectiva de Rancière, queremos acreditar que a EJA, enquanto modalidade e mesmo política educacional - e contrariamente ao que pressupunha Condorcet quer dotar o estudante de meios para que alce voos mais distantes e não se limite ao que a classe e o meio social teoricamente esperariam deles. Assim, espera-se, conforme a concepção trazida por Mejía, que cada vez mais se efetive uma educação de fato contextualizada, pressupondo-se que "o ato educativo [deve ter] um profundo respeito pelos saberes dos educandos [e] encerra em si a necessidade de uma formação permanente e de uma investigação crítica sobre a própria prática”. (MEJÍA, 2018, p. 197).

Assim, como já mencionamos acima, após a abordagem de alguns aspectos da obra de Mejía, espera-se que a EJA alcance e efetive a dignificação do "humano excluído e segregado por meios educativos e políticos pedagógicos como parte de construção de novos mundos", e 
não atue como mera política de manutenção da ordem social vigente, num viés meramente alfabetizador. Que a letra colocada em lei possa ser realidade transformadora e emancipatória dos cidadãos que dela necessitam e a ela recorrem.

\section{REFERÊNCIAS}

BOTO, Carlota. A escola do homem novo: entre o Iluminismo e a Revolução Francesa. São Paulo: Editora da Universidade Estadual Paulista, 1996.

BRANDÃO, Carlos Rodrigues. O que é o Método Paulo Freire. São Paulo: Editora Brasiliense, 1991.

BRASIL. Lei $\mathbf{n}^{0}$ 9.394, de 20 de dezembro de 1996. Estabelece as diretrizes e bases da educação nacional. Brasília, 1996. Disponível em:

http://www.planalto.gov.br/ccivil_03/leis/19394.htm. Acesso em: 10 set. 2021.

BRASIL. Diretrizes Curriculares Nacionais para a Educação de Jovens e Adultos. Parecer 11/2000. Brasília, 2000. Disponível em:

http://portal.mec.gov.br/secad/arquivos/pdf/eja/legislacao/parecer_11_2000.pdf. Acesso em: 10 set. 2021.

CONDORCET, Nicolas. Cinco memórias sobre a instrução pública. Tradução e apresentação Maria das Graças de Souza. São Paulo: Editora UNESP, 2008.

COSTA, Cláudia Borges; MACHADO, Maria Margarida. Políticas Públicas e Educação de Jovens e Adultos no Brasil. São Paulo: Editora Cortez, 2017.

FREIRE, Paulo. Pedagogia da autonomia: saberes necessários à prática educativa. São Paulo: Paz e Terra, 1996.

FREIRE, Paulo. Pedagogia do Oprimido. Rio de Janeiro: Paz e Terra, 2005.

KLEIN, Ana Quézia Roldão da Silva. Condorcet e a instrução pública: por uma escolarização gratuita, laica e universal. Revista de Espaço Acadêmico, n. 188, jan. 2017. Disponível em: https://periodicos.uem.br/ojs/index.php/EspacoAcademico/article/view/32410. Acesso em: 17 jan. 2020.

MEJÍA, Marco Raul. Educação e Pedagogias críticas a partir do Sul: cartografias da Educação Popular. São Carlos: Pedro \& João Editores, 2018.

MORAES, Marileia Gollo de. Mulheres analfabetas e inscrições de suas heranças: aproximações e distanciamentos na educação das suas filhas. 2018. $157 \mathrm{f}$. Tese (Doutorado em Educação) - Universidade Regional do Noroeste do Estado do Rio Grande do Sul, Ijuí, 2018. Disponível em:

http://bibliodigital.unijui.edu.br:8080/xmlui/handle/123456789/6067. Acesso em: 03 mar. 2020 . 
RANCIÈRE, Jacques. O mestre ignorante: cinco lições sobre a emancipação intelectual. 3. ed. São Paulo: Autêntica, 2015.

SANTOS, Rodison Roberto. Igualdade, liberdade e instrução pública em Condorcet. 2004. 142 f. Dissertação (Mestrado em Filosofia) - Universidade de São Paulo, São Paulo, 2007. Disponível em: https://teses.usp.br/teses/disponiveis/8/8133/tde-04032008103714/publico/DISSERTACAO_RODISON_ROBERTO_SANTOS.pdf. Acesso em: 23 fev. 2020 .

\section{Como referenciar este artigo}

FELDENS, D. G.; CORREIA, F. B.; TELES, P. S. Pensando aspectos da educação destinada a jovens e adultos a partir de Nicolas Condorcet, Jacques Ranciére, Marco Raul Mejía e Paulo Freire. Revista on line de Política e Gestão Educacional, Araraquara, v. 25, n. 3, p. 2933 2946, set./dez. 2021. e-ISSN:1519-9029. DOI: https://doi.org/10.22633/rpge.v25i3.15678

Submetido em: $25 / 08 / 2021$

Revisões requeridas em: 20/09/2021

Aprovado em: 22/10/2021

Publicado em: 08/12/2021 